\title{
The Quality Evaluation System Research Of Applied Undergraduate Colleges And Universities Practice Teaching Under The Background Of Transformation Development
}

\author{
Shengjiang Chen ${ }^{1}$, Chunfeng Zhang ${ }^{2, *}$ \\ ${ }^{1}$ School of Nuclear Technology and Chemistry \& Biology,Hubei University of Science and \\ Technology, Xianning, Hubei, China \\ ${ }^{2}$ School of Foreign Languages, Hubei University of Science and Technology, Xianning, Hubei, China \\ ${ }^{*}$ Corresponding author: Chunfeng Zhang
}

\begin{abstract}
Keywords: Transformation of development, Undergraduate colleges and universities, Practice teaching, Quality evaluation system
\end{abstract}

\begin{abstract}
This paper tries to eliminate different courses and professional difference, gives a panoramic view of the teachers engaged in teaching activities of the entire process, scientific review of the teaching process, the key point of the quantified evaluation index, compiled with distinctive oriented, scientific evaluation index system. On this basis, according to the characteristics of the evaluation index system, determine the different angle by the student evaluation, comprehensive evaluation and teacher self-evaluation, the evaluation of the main, in order to achieve the purpose of improving teaching quality.
\end{abstract}

\section{Introduction}

Teaching is the most important task of local colleges, and the quality of teaching is the core of school education quality. Teaching quality evaluation is a very important work, because each teachers are concerned about their own work achievement, hope the outside world will make fair and objective evaluation to their own work achievement, hope his labor value recognition, everyone are very concerned about their own teaching quality in colleges and universities, hoping to find weak link, and constantly improve its breakthrough [1]. Therefore the fair evaluation of teaching quality in colleges and universities or not, about whether can fully arouse the enthusiasm of teachers, improving the teaching quality, the evaluation of teachers' teaching quality and provide a basis for annual appraisal, but at present most of the college teaching evaluation exist strong subjectivity, the shortcomings of evaluation is not scientific [1]. There are many factors that can affect the quality of teaching; the fuzzy comprehensive evaluation method is affected by various factors of things to make comprehensive evaluation of a very effective method.

\section{The present situation and problems of the practice teaching quality evaluation in colleges and} universities

For the evaluation of teaching quality in colleges and universities is not value. Colleges and universities for faculty performance evaluation is basically there are two parts in teaching and scientific research. Most colleges and universities focus on scientific research and the number of papers and teaching work, rather than to evaluate teachers' teaching quality [2]. This evaluation system is not in accordance with the purpose of the evaluation, evaluation of teachers should be focusing on the analysis of teachers' teaching quality and teaching, teaching attitude, rather than evaluate his professional level and scientific research ability. As a result, led to the paper, there are few original achievement, blundering wind filled in colleges and universities; College teachers lack of energy input to the teaching, teachers "education" function decline.

The lack of scientific evaluation index system. The university teachers' teaching quality evaluation of macro policy is lack, as a direct result of the lack of scientific evaluation index system. In colleges and universities, students rely on the average, the supervision of the school and the leading 
cadre to evaluate teachers' teaching quality, but the school supervision and a limited number of leading cadre's classes, small coverage, and standard is difficult to determine. Students are the main body of education that is a very important aspect [2]. But also want to see, student to teacher's teaching quality are not necessarily an understanding of the objective and comprehensive, especially just at the end of the course, the student to a teacher's teaching quality evaluation is often take a long time to consider, even after the graduation to society will have a more profound experience, after many lectures, shallow on the platform unctuous, examination of "water" get high scores, teachers tend to be student ratings and teaching meticulously, strict in students, high teaching level of teachers, students often get high evaluation. In colleges and universities, the teacher can't tube, don't want to tube and blindly cater to students, to students for their high score. This not only can not improve the quality of teaching, also can cause the ruin teaching style.

Evaluation method is lack of operability. University teachers' teaching quality evaluation at present has not yet found a real applicability evaluation method is very strong, easy to operation [3]. University teachers' teaching quality evaluation should adopt qualitative and quantitative combined, usually combined with a regular, leadership and supervision Way, but in the current universities, teachers teaching quality evaluation is often point to area, and to the lack of the evaluation of different levels, different Angle of view for organic arrangement, make up for each other, complement each other, form a relatively complete and comprehensive evaluation results.

The evaluation result is not high. Teachers teaching quality evaluation as a result, how to better with post appointment, performance appraisal and assessment, is an important problem of the evaluation work [3]. Evaluation result is not with the cultivation of teachers, assessment Ping Xian, post appointment, pay-for-performance practical treatment such as hook [2]. Because evaluation becomes a mere formality, the evaluation results into a decoration.

\section{The teaching quality research significance of university teacher evaluation}

At present, in the increasingly competitive environment, the quality of teaching is to cultivate talents quality relates to the survival and development of the school [3]. And the teaching quality is the process through a series of teaching activities, many teachers and students through the development and change of the reflected, the teaching quality of teachers directly affect the quality of the students, the evaluation of teaching quality of teachers, promoting the improvement of the teaching quality, is basic guarantee of improving students' Comprehensive quality. Known as the "father of modern education evaluation of Taylor" was put forward: the evaluation process is essentially a set curriculum and teaching plan to the actual education. There are two main points: one is to evaluate the; the two is the development of. Therefore, evaluation of teaching quality is a very important aspect, the evaluation process is to make judgments about people being evaluated. Study on the evaluation of teaching quality is very important, mainly in the following aspects:

Encourage teachers to improve their teaching, to promote the professional development of teachers. On Teachers' teaching quality evaluation of fundamental purpose is to promote the teachers constantly gaps, improve teaching, to improve the quality of teaching [4]. In addition, teachers constantly enrich and improve their professional knowledge, will effectively promote the professional development of teachers.

Teaching management improvement. Can make the school teaching management departments to understand teaching situation, found the problem, sum up experience, and improve the work, in order to achieve the purpose of improving teaching quality [4]. Evaluation is a very effective means of management, the school teaching management departments can understand teaching situation through the evaluation of teaching quality control, timely, in order to achieve the aim of personnel training.

Strengthen school teacher performance management. An important function of evaluation is to provide the basis for Jiang you, according to the teachers' teaching quality evaluation results; to set up an effective incentive mechanism within the school, finally lay the foundation to ensure the quality of teaching. 
Teaching quality evaluation. The teachers' teaching quality evaluation is an important part of college teaching quality monitoring and evaluation system, evaluation of teachers' teaching quality is helpful to improve the teaching quality monitoring and security system [4]. Monitoring the teaching quality in Colleges and universities is mainly implemented by examination and evaluation, teaching quality evaluation is the key, only an objective and impartial evaluation of teachers teaching quality, in order to further improve the teaching quality monitoring and security system.

In summary, the object of teachers' teaching quality assessment is the teacher, also has very important significance to the school management. But we should also see, the evaluation of teachers' teaching quality foothold in the student body, the fundamental purpose is to improve students' learning ability, culture has the solid specialized foundation charity, has the independent personality and creative spirit of students.

\section{Establishes the evaluation index system of university teaching quality principle}

The directional principle. To develop the "application" innovative talents as the guidance, follow the law of education, the education reform and development, to reflect the systematic and comprehensive training objectives [5].

General principle. Evaluation object is all college part-time teachers to undertake the task of teaching, which is applicable to all the teachers to undertake the task of teaching [5]. Therefore, this study tries to eliminate different courses and professional difference, gives a panoramic view of the teachers engaged in teaching activities of the entire process, scientific review of teachers engaged in teaching activities of the entire process, that is from the beginning of the teaching activities of the compilation of teaching outline, teaching plan, selection of materials to teaching, courseware preparation, until classroom teaching and tutoring students, course, course the sum of all the teaching key point of quantitative indicators for the evaluation of teaching quality, in order to examine the teachers, developed with distinct orientation evaluation index system.

The scientific principle. The theory of effective teaching abroad and domestic research results, extensive interviews in the school management, teachers, students, basic collection, summary and analysis of relevant literature, the connotation of each index was batted [6]. The index expression is as clear and interrelated with each other, form an organic whole, evaluation criteria not only conforms to the realistic and objective comprehensive, teachers can meet the requirements through the efforts, has been widely recognized by the students.

The operating principle. Specifically, there are three aspects: one is the evaluation index should be consistent with the actual, practical characteristics, embodies the teachers teaching and reflect the characteristics of the current high education in China; the number two is the appropriate index system, which reflects the process of teachers' teaching and can catch the key point; three is the evaluation index quantified as far as possible in order to operate in the evaluation process, the implementation [6].

Dynamic principle. For teacher's teaching quality evaluation is a dynamic process, with the development of science and technology, the change of education objects, in aspects such as teaching contents, teaching methods, teaching means reform continuously, the evaluation index must be dynamic and development. Therefore, the evaluation result feedback analysis, using both a appraisal cycle, the end of the beginning of the next round of evaluation work [5]. In the process, teaching management to analyze the evaluation results, according to the actual situation of the change of evaluation index system of proper adjustment, to ensure the validity of the evaluation.

\section{The content of the university teachers' teaching quality evaluation}

Teaching process, the relationship between teachers and students is relatively complex, the factors influencing the quality of teaching is also more, generally speaking, the more closely related factors of teaching organization, structure, the relationship between teachers and students, and teachers' teaching skills, teaching effect, etc., can be summarized as the teaching aim, attitude, content, method, effect and so on five aspects. 
Teaching objectives. Target of personnel training is a beauty. Intelligence and physique full scale development have certain professional knowledge of the innovative talents. For their training is through each course, each of the education teaching [7]. Teachers on the basis of the theory in accordance with the stipulations of the syllabus, besides the teaching of basic knowledge, basic skills, but also focus on training students' ability and innovative spirit, as well as regular student political thought and professional ideas, which can be embodied in every link of teaching. College teachers to grasp the business ideas, do both teaching and educating.

Teaching attitude. The teaching attitude is the key to ensure the quality of teaching. As a college teacher, should love the labor of duty, loyalty education career, so as to actively take the teaching tasks, assiduously, overcome difficulties and strive to improve the teaching quality [7]. Otherwise, if just take teaching as a means of making a living or as a ladder, for the sake of fame is never do a good job in teaching. Prepares a lesson earnestly, according to their aptitude in the teaching, to deepen our understanding of students, students, carefully choosing teaching contents, summarize unceasingly, have the courage to explore, concerned about love students, a teacher by worthy example, teaching, and form the teaching of business acumen.

The teaching content [8]. 1) Teaching content is the core to ensure the quality of teaching, the teacher in the process of organizing teaching, first of all to ensure the scientific nature of the teaching content. Teaching content should be accurate, so, must not be repeated. 2) Teaching content should be reflecting the materialist dialectics and patriotism, to teaching. 3) Teaching content should be constantly updated to base on the forefront of The Times, reflecting the new level of science and technology development, to a certain depth, breadth and forward-looking. 4) Teaching content should be to integrate theory with practice, and to cultivate students' practical application ability, knowledge, improve the effect of learning.

The teaching method. Teaching method is the effective measure to ensure the quality of teaching, a careful organization of teaching must match with the appropriate teaching methods. Especially in the teaching to grasp the college students' psychological physiological characteristics, elaborate design, pay attention to the heuristic teaching [8]. Because college students' understanding ability is strong, so must be good at using the contradiction between the old and new knowledge, students use, cutting untrustworthy, and disambiguation, guide students to discover problems, analyze and solve problems, cultivate learning enthusiasm, promote the development of thinking. Second note step by step, according to the curriculum system, chapter, order, step by step, the teacher according to students' cognitive level, cognitive ability, flexible use of teaching principle, make the students to accumulate knowledge solidly, developing the intelligence. Again, pay attention to the theory with practice, earnestly practiced more. The teacher wants to highlight, the difficulties in breakthrough, increase students' practice time and opportunity, causes the student to use it, the lines. Finally, using a variety of teaching media should pay attention to in teaching [8]. Due to the modern teaching media emerge in endlessly, such as projection, slide show, TV, video, computer, tape recorder, etc. , all kinds of media types on the way of expression, therefore in the teaching to properly use a variety of media, fully reflect the teaching content, to mobilize students' various senses, so as to achieve optimal teaching quality.

The teaching effect. The teaching effect is the key to the evaluation of teaching quality, everything revolves around gain good teaching effect. When evaluating the quality of teaching effect, generally can be conducted from three aspects [6]:

The student behavior. In a vivid lesson, the students showed great interest and attention, and will actively participate in discussions, take good notes carefully and do exercises, etc., and seldom has desertion, fidgeting. Therefore in the process of teaching can adopt the method of observation, record the student's words and deeds, and from students' explicit characteristics reflect the quality of teaching.

The students' attitude. Through teaching, students in attitudes will influence and change, such as deepen the understanding of curriculum and learning, and thus can be used in a questionnaire survey, with the change of attitude scale analysis on students attitude. 
The improvement of students' cognitive level. Through learning, students have to improve on knowledge, and can pass the examination test data. So when evaluating the effect from various comprehensive investigations, pay particular attention to the students' feedback, so as to truly reflect the quality of teaching.

\section{Summary}

Teacher's teaching quality evaluation is a very complicated work, hierarchy and multi-azimuth to establish a comprehensive and integrated teaching quality evaluation system, to the teacher's teaching quality evaluation results of reasonable, make the teaching quality evaluation work really giving play to the role of guidance, motivation, and really promote the improvement of teaching quality, cultivate high quality talent.

\section{Acknowledgement}

Fund project: Teaching research project of Hubei province 2015 (Fund number: 2015 - S - 01).

\section{References}

[1] Zh. B. Yu, High education management, Shanghai Jiaotong university press, 2008, pp. 23-27.

[2] T. X. Xue, The high education management, east China normal university press, 2014, pp. 34-37.

[3] B. H. Huang, The developmental teacher evaluation system, Shanghai: east China normal university press, 2011, pp. 67-70.

[4] Sh. M. Liu, High education goals of management, Beijing normal university press, 2008, pp. $55-58$.

[5] Y. J. Yang, High education evaluation principle and method, Shaanxi normal university press, 2013, pp. 12-16.

[6] H. Wei and J. L. Shen, The characteristics of effective teaching analysis in college teachers, Journal of southwest normal university, 2012, vol. 5, pp. 45-48.

[7] Ch. L. Li, University teachers' teaching level evaluation in the practice of China's development and theory discussion, The modern education science, 2015, vol. 4, pp. 30-34.

[8] Ch. H. Xu and S. W. Yang, Thinking of teachers teaching quality evaluation, China's high education research, 2013, vol. 2, pp. 83-87. 